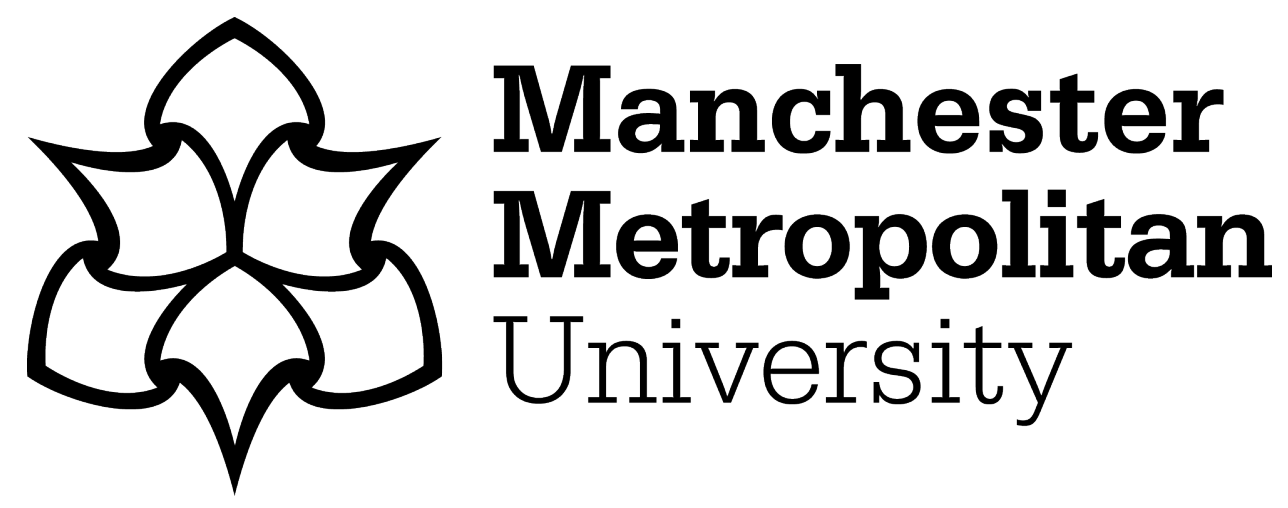

Hackett, AC, MacRae, C, McCall, K, Penfold, L, Wallis, N, Bates, E and Cooke, $L$ (2018) Coda: posthumous conversations. A reading group to discuss the work of Dr Elee Kirk. Children's Geographies, 16 (5). pp. 571-577. ISSN 1473-3285

Downloaded from: https://e-space.mmu.ac.uk/621202/

Version: Accepted Version

Publisher: Taylor \& Francis (Routledge)

DOI: https://doi.org/10.1080/14733285.2018.1497142

Please cite the published version 


\title{
Coda: Posthumous conversations. A reading group to discuss the work of Dr Elee Kirk.
}

Abigail Hackett, Christina MacRae, Katy McCall, Louisa Penfold, Nicola Wallis, Elaine Bates, Lucy Rose.

This paper is accepted to the journal Children's Geographies.

NB This is the author final copy of the manuscript, prior to copyediting and typesetting by the journal. The final published version will contain minor typographic changes and correct pagination. If you wish to quote from the paper, please access the final PDF version via the journal website: https://www.tandfonline.com/loi/cchg20

If you are not able to access the paper because you do not have a subscription to the journal, please contact the authors.

\begin{abstract}
In May 2017, a group of museum researchers and practitioners met to discuss the writing of Elee Kirk (1977-2016), whose pioneering doctoral study of young children visiting a natural history museum connects with our own work and practice in a number of different ways. Kirk (2015) advocates for research that views children's everyday museum visiting "beyond their potential for learning." (p.238). This paper offers edited transcripts of the discussion sparked by reading Kirk (2015), documenting the conversation under a number of themes that emerged during the discussion, and reflecting on how each are picked up in more detail by the papers in this Special Issue.
\end{abstract}

In May 2017, a group of museum researchers and practitioners met to discuss the writing of Elee Kirk, whose pioneering doctoral study of young children visiting a natural history museum connects with our own work and practice in a number of different ways. Elee presented a keynote at the 'Research Methods for Exploring Children's Experiences in Museums' conference held in May 2016, one of the impetuses for this special issue. Although we did not know at the time, this would be amongst the last occasions Elee presented her research, as she sadly passed away on $1^{\text {st }}$ August 2016. Her untimely death, due to cancer, meant that she would not be able to personally write a contribution to this special issue, or be involved in its guest editing, both things we would very much have liked. Elee devoted energy in the last months of her life to disseminating her research, with the 
aspiration it would benefit future museum practitioners, researchers and visitors ${ }^{1}$. We wanted to include these conversations about Elee's work in the special issue to honour Elee's memory, and to represent her work in this special issue, without which a current account of influential research on children in museums would be incomplete.

The context of Elee's original doctoral research is as follows;

The research was carried out during 2011 in the Oxford University Museum of Natural History and involved recruiting families with children aged four or five years as they entered the museum, and asking the children if they would use my digital camera to photograph things they liked or found interesting. They were then left to enjoy their visit as they would normally. At the end of the visit, the family re-joined me, and the children and I looked together at their photographs on a laptop as I recorded our conversation about the museum, using the pictures as a starting point. In total the project included 32 children - an equal mix of girls and boys who produced between them 1,597 photographs - an average of 50 photographs per child, ranging from a minimum of seven photographs, to a maximum of 219.

Kirk, 2015, P.239

As a group, we focussed on the following book chapter, which had been the basis for Elee's keynote presentation at the conference:

Kirk, E (2015) “Budding Photographers: Young children's digital photography in a museum", in Stylianou-Lambert, T. (ed.), Museums and Visitor Photography: Redefining the Visitor Experience, MuseumsEtc.

Elee's work was particularly concerned with methodologies for understanding children's experiences in museums, and this book chapter tackles this concern directly. Firstly, Elee argues for research methodologies that account for something broader than children's learning in museums, advocating

\footnotetext{
${ }^{1}$ Read more about Elee Kirk's research at www.eleekirk.com. Her book, Snapshots of Museum Experience: Understanding Child Visitors Through Photography is due to be published by Routledge in the autumn of 2018.
} 
for research that "sees the children as visitors in their own right, and which is interested in everyday children's visits beyond their potential for learning." (p.238). Secondly, Elee insists that different research methods work differently in different contexts, and goes on to illustrate why photography, as opposed to other child-centred research methods, was required for her particular study.

In the following sections, we offer edited extracts of our discussion sparked by reading Elee's work. We have documented the conversations under a number of themes that emerged during the discussion, and reflect on how each are picked up in more detail by the papers in this Special Issue. We go on to consider the wider implications for understanding children's perspectives in museums, the nature of the visual in research, and implications for us, as researchers and practitioners, in terms of our museum practice with young children in museums. Extracts from our original group discussion are included below in italics. In each section, we also trace links between the themes discussed from Elee's book chapter and the wider contributions in this special issue.

\title{
The particularity of research with children in museums
}

\begin{abstract}
“Because this research focused beyond children's learning, it has been possible to pay attention to the varied and unexpected elements of their visits, and this chapter will specifically focus on the relationship between the children and the camera itself within the museum context."
\end{abstract}

Kirk, 2015, p.238

I really connected with the mosaic approach, and how she trialled different methods, but it was the photography that really connected. It doesn't require someone external like a gallery member to come in and do something - we know children learn best with parents or the adults in their life they know best, so photography is something they can do with them. It seemed to have two really key different purposes - one around extracting children's experiences in the museum in a really different way - not around children's cognitive learning around a particular object, but wider processes, in a really multi layered way. So thinking about the mosaic approach, but how does that work with little kids and families, and in this particular context of the museum? And I would say that really connects with my experience of researching young children in galleries as well - photography is a very powerful tool. 
Sometimes, with photography in museums, teachers get anxious because they feel that the children are missing out, by seeing everything through a screen. Whereas here it was saying, the cameras weren't a distraction.

[Taking photographs] makes you focus and choose - it's like choosing isn't it?

And, in that way, it's different from putting a go-pro on their heads - with holding a camera and taking the pictures there is a selection process, saying "this is saying something".

"One of the most basic decisions made in taking a photograph is choosing the subject. However, a review of the children's photographs suggests that their perceptions of what a photograph is of differ subtly from those of an adult, which leads to subsequent differences in the unspoken rules of how to compose a photograph........Not only does the subject tend to be in the centre of the children's photographs, but it seems a further unspoken rule is that their photographs tend to each have only a single intended subject...... And where a child wanted to photograph two things next to each other, they would often photograph them individually, with the intended subject in the middle of the picture, even when both specimens could easily have fitted into one picture."

Kirk, 2015, p.248

It was interesting how she talked about them trying to get the object in the frame of the picture. I had some children in my research in a classroom who would take the photos seemingly randomly and then look back to see what they had captured. So I wondered if it was something about being in a museum, they have already got the idea that the object is the main purpose of what they are going to see. To me the objects photographed in this study seemed incredibly well framed compared to photos I had been looking at.

I wonder if the museum display helps support that, placing objects in cases indicates "this is the thing to look at".

Space is organised in a really different way in a museum. 
So it's about being specific to the place, and what sorts of methods work well.

Elee's chapter makes the case for photography as being the best method for this particular research, in this particular context. This led to rich discussions on the notion of the particularity of a museum as a site for research with children. How are things such as childhood, space, objects and photography differently assembled, conceptualised and understood in a museum, as opposed to, for example a school classroom? The notion of the particularity of a museum as a location for young children's activities or explorations is intriguing, and is taken up by a number of papers in this special issue. For example, for Birch the organisation of museum space and the sensory encounter of this is crucial, particularly for children, who have an "aesthetic-affective openness" (Bennet, 2010, cited in Birch, forthcoming). Yamada-Rice (forthcoming) demonstrates the sensoriality of how children explore places with their bodies, and Carr et al. (forthcoming) stress the agency of objects within a museum. Carr et al. cite Ingold's notion of "a place where several goings on become entwined" (Ingold, 2010, p.96 cited in Carr et al.), which may be a fruitful starting point for thinking about the specificity of a museum as a site for research with children.

\title{
Children's perspectives
}

\begin{abstract}
"Mizen (2005) states that the camera puts the viewer visually in the children's shoes, and within this research some photographs certainly showed how children viewed elements of the museum differently from adults. In addition, the photographs also allowed the children to discuss aspects of their visit that were unknown to their parents."
\end{abstract}

Kirk, 2015 p.243

The use of the photos as the method, coupled with the fact that the child had the camera, resulted in a focus of the attention on the view of the child, but very subtly, rather than explicitly asking parents to be led by their child. Maybe these cameras started discussions with the adults asking the children why they had taken certain photos. Perhaps without the camera, those conversations would have happened differently, and been more adult led. I remember one of the really powerful things Elee talked about last year was seeing children as visitors in their own right, rather than being with their parents. Of course they don't come to the museum alone, but they do have ideas to contribute of their own. So that has shaped how I'm looking at my future planning, thinking is this a family activity 
or is it a child centred one - both are valuable, both are useful, but once I know which it is to be, that can help me shape it better.

We just finished a study looking at families visiting museum sites, and one of the findings was the way the focus seemed to shift across the visits. There would be points in the visit that were very orientated towards the kids, points where the adults were really interested in something and leaving the kids to it because they wanted to look, and points that were very much about this is something we are doing together. And there was a rhythm to that, even just across one visit to one site.

The methods in Elee's research could been seen as a starting point for looking at things through a child's eyes, maybe thinking about where could you go next - would it be another visit to this museum or do you want to go and see the animal now in life? Or thinking of how to follow the child's lead in a very broad way.

Understanding children as visitors in their own right, who may influence or be influenced by other humans and non-humans during their museum visit, is central to many of the papers in this special issue. Birch demonstrates the complexity of designing spaces for children, moving beyond concerns around ease of use for smaller bodies, in order to confront the "hegemony of adult ownership of public places". As Kelton et al. (forthcoming), and Hackett et al. (forthcoming) show, children's experience in museums can be shaped by other children, by adults, by the physicality of spaces, yet in turn, children themselves can shape or frame the experience of adults in their groups, and change space itself through their place-making activities. Papers by Birch (forthcoming) and MacRae et al. (forthcoming), in particular, interrogate how children are conceptually framed as key to how researchers can encounter or recognise the experiences of children in museums. MacRae et al. offer alternative conceptual framings that may enable researchers to account for intensities, illogicalities and 'inexplicable somethings' when children visit museums.

\section{Thinking about the visual in museums}

I would also suggest that the reason people take photographs in museums is to remember, share and discuss their experiences and the things they saw, and this is exactly what the children were being asked to do with their photographs.

Kirk, 2015, p.241 
I've got to sell my programme at Manchester Art Gallery and there's hundreds and hundreds of photographs, mostly showing what happens in the sessions. So I'm having to think like a marketing person, thinking what do I want this to say about my programme - I want it to be about materials, and engagement.

It's telling a story isn't it?

And it's still that element of choosing, that element of "what does this image signify?" that is paralleled in the chapter. In that way, it's the same sort of process the kids are going through -that process of choosing and signifying.

I wonder if there scope to tap into that in terms of curation. It we are thinking about what images to keep and which to discard - that's the same as a process of curation - selecting things we think are the most important, the most representative. Maybe there scope to tap into that - because children are able to make those value judgements, because that is what they are doing with their photos. One of the things that came out the chapter was this surprise at children's skills in things like framing the pictures, and making quite specific decisions about how they are going to represent what they needed to represent, which was kind of a surprise to the researcher and then is a surprise as you read it. You have got to leave space for that.

As the above discussion shows, the visual in museum practice and research can work in a number of different ways. Video data and photographs are increasingly important to research with children in museums, enabling researchers to focus on place, objects and the body in new ways. In addition, visual data can be revisited years later to reconsider the same event from different theoretical perspectives, as MacRae et al. (forthcoming) demonstrate, or worked with in fine grained detail to offer insights that would be not been possible in real time, as with Kelton et al.'s (forthcoming) research. In addition, presenting research findings in visual modes offers new possibilities to opening up these conversations, as the papers by Clayton and Shuttleworth (forthcoming) and Yamada-Rice (forthcoming) demonstrate.

\section{An improvisatory practice: Working with young children in museums}


One of the advantages of photography as a tool for museum engagement is that it can allow young children to direct their own and their family's attention to the exhibits.

Kirk, 2015, p.259

It's finding that balance between a child's explorations and I guess that thing with the museum or gallery and what it offers around concepts, technique and how we bring that all together. It's a balance and there's not one clear cut form to find that balance, its constantly changing so we always need to be discussing and thinking on our feet and reconsidering what we are doing for young children and how and why that's happening.

And it makes us look at what children do - if they are looking for a train or some bricks, something familiar. People are showing us that they are looking for that kind of familiarity.

Maybe quality is improvisational practice. It's something we don't talk about much at the moment because we are so worried about all our outcomes and plans and targets. There is something at the core, which is about really being able to improvise quite quickly in relation to both parents and children. Which is a difficult quality. But we are constantly trying to pin things down and maybe it's about being able to improvise.

And it comes through experience of working with children and families I think.

I'm sure we do that a lot when we are working with small children, but we don't really talk about it, it's not something we value.

I wonder if people don't realise they are doing it because It's very natural, it's like an embodied experience, like moving or walked.

It's not so much an intellectual thinking through, 'oh I'm extending this child's learning'

It's more like the way you would step over a puddle, you would not be thinking "how far do I need to move my leg", you would just naturally see things, and if the child shows no interest, you know the point at which to try and interest them and when to pull back. 
The importance of "thinking on our feet", or of improvisatory practice, is taken up by several papers in this special issue. Birch (forthcoming) and Hackett et al. (forthcoming) each, in different ways, caution against an approach of generalizable recommendations, guidelines or checklists for young children in museums. Of all the papers in this collection, Clayton and Shuttleworth (forthcoming) perhaps address the question of implications for practice most directly. Stressing the importance of serendipity, they offer the conceptual frame of climate, landscape and landmark to consider how practitioners plan or make available experiences and spaces for families with young children. As practice with young children in museums grows in significance and priority for many museums, both here in the UK and internationally, we look forward to seeing what improvisatory, serendipitous practice, which is tacit and embodied, builds on experience and involves thinking on our feet, could look like in museums in the future. Borrowing from Clayton and Shuttleworth's paper we urge readers to "Plan for possibilities, but embrace the things you can't plan for......Allow for chance and imagination. You will be inspired."

\title{
Concluding thoughts
}

\author{
"One of the most important lessons I have drawn from this project is that \\ the success of research (and education, evaluation and visitor engagement) \\ can be increased by working with visitors in ways that make sense to \\ them."
}

Kirk, 2015, p.261

Projects like this are helpful in moving towards a better understanding that even very little children have things to offer, they have something to say, and valuing their contributions is important. And this project really showed that -it's very respectful towards the children's ideas, the different ways that families interpreted it.

The paper does highlight the real possibilities and challenges of using photography. Elee makes a significant contribution because so little has been written about young children and photography in galleries, so in that sense it is significant in how it helps us think about young children in galleries.

I agree, although it is talking specifically about photography, it has wider implications about perception, about control and I think it was interesting how she discusses when children are in a museum setting they behave differently, and I think that's probably true of all visitors really. And 
then giving the camera to the child, that affected them as well, it affected the whole family and their experience of the visit. So there are ripples that go a long way from this very specific project.

When Elee was carrying out her doctoral research, the numbers of academic researchers who had previously studied young children's experiences in museums could be counted on one hand. As the papers in this special issue demonstrate, the field of young children in museums has grown in exciting ways in the last ten years, not just in terms of quantity, but in terms of methodological innovation, theoretical scope and conceptual approach. Certainly, Elee was one of the best at eloquently making the case for this work, connecting research theory with museum practice, and gently encouraging the museum sector to be a little braver and more radical in how we think about young children in museums, whilst never overlooking the fantastic practice that is already taking place. In this Coda, we have traced some of the ways in which ideas present in Elee's work have implications for this emerging field of research, for academics and museum practitioners, and how some of these have been taken up and taken forward by the contributors to this journal. We hope this Special Issue represents one of the 'ripples' created by Elee's work, and the work of those who had the pleasure of sharing and discussing research and ideas with her.

\section{Contributors to the discussion:}

Abi Hackett is Research Fellow at Manchester Metropolitan University. Her research focusses on young children in museums, and early childhood literacy practices more broadly.

Christina MacRae is Research Fellow at Manchester Metropolitan University. Her research focusses on 2 year-olds in nursery settings, and young children in museums.

Katy McCall is Family Learning Manager at Manchester Art Gallery where she programmes an innovative and broad programme that aims to include families from across the city.

Louisa Penfold is an independent children's curator currently undertaking her doctorate in the School of Education at the University of Nottingham, in partnership with the Whitworth Art Gallery and Tate. 
Nicola Wallis is a Museum Teacher at the Fitzwilliam Museum in Cambridge, where she leads on working with children in the Early Years.

Elaine Bates is the Early Years coordinator at Manchester Museum .She has undertaken MA research with young children and families in the museum using natural history collections to support a connection to nature.

Lucy Rose is the Under 5s Learning Co-ordinator for East Riding of Yorkshire Museums Service. She plans and runs events for under 5 s, adds to family programming, and improves the accessibility of exhibitions for this age group.

\section{References}

Birch, J. forthcoming. "Museum spaces and experiences for children - ambiguity and uncertainty in defining the space, the child and the experience." Children's Geographies.

Carr, M. Cowie, B. Clarkin-Phillips, J. Gardner, S. Soutar, B. Clayton, L. Wipaki, M. Wipaki, R. forthcoming. "Young children visiting museums: exhibits, children and teachers co-author the journey." Children's Geographies.

Clayton, E. and Shuttleworth, J. forthcoming. "Spaces In-between." Children's Geographies.

Hackett, A. Procter, L. and Kummerfeld, R. forthcoming. “Exploring Abstract, Physical, Social and Embodied Space: developing an approach for analysing museum spaces for young children." Children's Geographies.

Kelton, M. Ma, J. Y. Rawlings, C. Rhodehamel, B. Saraniero, P. and Nemirovsky, R. forthcoming. “Family Meshworks: Children's Geographies and Collective Ambulatory Sense-Making in an Immersive Mathematics Exhibition." Children's Geographies.

Kirk, E. 2015. “Budding Photographers: Young children's digital photography in a museum", in Stylianou-Lambert, T. (ed.), Museums and Visitor Photography: Redefining the Visitor Experience, MuseumsEtc. 
Kirk, E. 2016. "Exploring young children's museum experiences through their own photographs". Keynote presentation at Research methods for exploring children's experiences of museums, May 2016, Sheffield.

Macrae, C. Hackett, A. Holmes, R. and Jones, L. 2017. “Vibrancy, repetition, movement: Posthuman theories for reconceptualising young children in museums." Children's Geographies.

Yamada-Rice, D. forthcoming. "Licking Planets and Stomping on Buildings: children's interactions with curated spaces in virtual reality." Children's Geographies. 